\title{
The Crack Evolution of Red Clay under Wet and Dry Cycles
}

\author{
Kaisheng Chen ${ }^{1, a^{*}}$, Zhen $L u^{2, b}$ \\ ${ }^{1}$ School of Civil Engineering, Guizhou University Guizhou Guiyang China \\ ${ }^{2}$ School of Civil Engineering, Guizhou University Guizhou Guiyang China \\ achen_kaisheng@163.com, 'bu_zhenqiaosui@163.com
}

Key word:wet and dry cycles, red clay, image-manipulation, crack

Abstract.The red clay has high moisture content,high plasticity,high void ratio and other special engineering properties,especially when the subgrade surface dehydrates,it shrinks and cracks,caused the subgrade to have some diseases.Taking the subgrade filling from the Liupanshui inner Expressway as the research object,doing the experiment during wet and dry cycles when the red clay on the condition of $105^{\circ} \mathrm{C}$ and $34^{\circ} \mathrm{C}$, and researching the relationship between the fissure ratio and the cycle index under wet and dry cycles.Research shown that the fissure ratio increasing with the increasing of the numbers of the wet and dry cycles, in the first two cycles it increased significantly, the last three cycles increased slowly, this phenomenon shows that the influence of the first two cycles on the crack of red clay is larger.That the ratio of the fissure ratio under the condition of $34^{\circ} \mathrm{C}$ to under the condition of $105^{\circ} \mathrm{C}$ increasing fast with the increasing of the moisture content and then reduce,reaching the maximum when the moisture content is optimum moisture content.

\section{Foreword}

Because the red clay has high moisture content, high plasticity, high void ratio and other special engineering properties, with the operation time of the highway growing,the subgrade and pavement has some diseases.The Guiyang-Zunyi Expressway,the Guiyang-Bijie Expressway and some other expressways have a lot of ruts. In the survey we also found that a large number of pavement cracks, the crack size is different and the crack shape is irregular, the most serious crack is the vertical crack caused by sink,the length of the crack is more than a hundred meters, the pavement also has large area subsidence,these all mainly casued by subgrsde subsidence.There also has some problems of different degrees of red clay in other roads has been built outside Guizhou province.Such as 107 National Highway in Moyang, the semi-rigid type base,the surface course and the cement pavement always appear cracks,slab pumping and crack slab.During the construction of the Beijing-Zhuhai Expressway between Moyang and Yizhang using a lot of red clay to filling embankment near Yizhang,making the embankment surface appear serious shape crack and fissure,the crack size is different, the maximum width is up to five to six centimeters, depth is up to twenty-six centimeters. The fundamental reason of subgrade pavement cracking is the red clay shrink because of the soil water loss under wet and dry cycles. So the research of the crack evolution of red clay under wet and dry cycles has a practical significance on highway construction in red clay area. 


\section{Basic physical properties of Red clay}

The soil samples adopted by this experiment was taken from Liupanshui inner Expressway third section.Soil characteristics as follows:brownish red,wet,the homogeneous soil,the compact structure, with certain small wormholes and the wholes of plant roots.On the grain composition,most is the silty clay.According to the Test methods of soils for Highway Engineering (JTG E40-2007), the basic physical properties of the soil is shown in Table 1.

Table 1 Basic physical properties of red clay

\begin{tabular}{|c|c|c|c|c|c|}
\hline \multirow{2}{*}{ JTG E40-2007 } & $>0.075 \mathrm{~mm} / \%$ & \multicolumn{2}{|c|}{$0.074 \sim 0.002 \mathrm{~mm} / \%$} & \multicolumn{2}{|c|}{$<0.002 \mathrm{~mm} / \%$} \\
\cline { 2 - 6 } & 17.25 & \multicolumn{2}{|c|}{71.41} & \multicolumn{2}{|c|}{11.34} \\
\hline $\begin{array}{c}\text { Optimum } \\
\text { moisture } \\
\text { content/\% }\end{array}$ & $\begin{array}{c}\text { Maximum } \\
\text { dry unit weight } \\
\mathrm{g} / \mathrm{cm}^{3}\end{array}$ & $\begin{array}{c}\text { Plastic } \\
\text { limit/\% }\end{array}$ & $\begin{array}{c}\text { Liquid } \\
\text { limit/\% }\end{array}$ & $\begin{array}{c}\text { oefficient } \\
\text { of } \\
\text { nonuniformity }\end{array}$ & $\begin{array}{c}\text { Coefficient } \\
\text { of } \\
\text { curvature }\end{array}$ \\
\hline 37.2 & 1.46 & 38 & 59 & 9.38 & 1.6 \\
\hline
\end{tabular}

\section{Testing Program}

\section{(1)Sample Preparation}

Using the proctor compaction test to make the sample which the degree of compaction is $75 \%$, the moisture content are $30 \%, 34 \%, 37.2 \%, 40 \%$ and $44 \%$. The sample's diameter is $150 \mathrm{~mm}$ and the height is $120 \mathrm{~mm}$.

(2)The test method under wet and dry cycles

Dry process: Under the condition of $34^{\circ} \mathrm{C}$ and $105^{\circ} \mathrm{C}$, put the sample in the oven, drying the sample(untill moisture content is less than 1\%)

Wet process:Calculating the amount of water needed, use the syringe adding water to the initial water content. The test method under wet and dry cycles shown in Fig. 1.

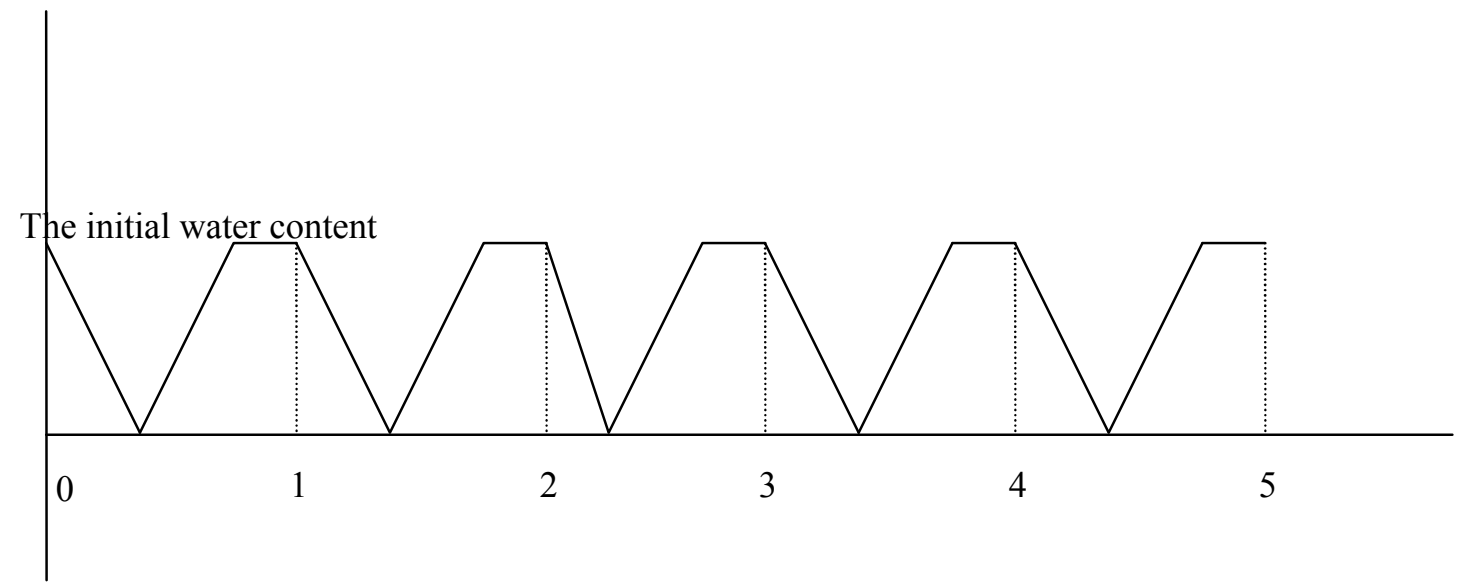

Fig. 1The test method under wet and dry cycles

(3)The definition of the fissure ratio. 


$$
\begin{gathered}
\text { The fissure ratio }=\frac{\text { The number of black pixels }}{\text { The number of pixels }} \\
=\frac{\text { The number of black pixels }}{\text { The number of black pixels }+ \text { The number of white pixels }}=\frac{\text { crack area }}{\text { sample area }}
\end{gathered}
$$

(4)Image manipulation

Analysing the whole sample area when doing the image processing. The contrast of color between the cracking partial soil sample and the not cracking partial soil sample is obvious.So using the gray entropy do the quantitative analysis to the crack in the soil sample.Taking the great advantage of the function of processing pictures of certain software,by the transformation the grayscale of the original picture,edge detection and median filtering and other measures,ultimately,offering the binary image transformed.The concert process:11 Invoking function \{imread\} to netlist the true color image into MATLAB and transforming it into digital image; (2) Invoking function \{improper\}, clipping the digital image; (3)Invoking function $\{$ rgb2gray\},transforming the digital image into the grayscale image; (4)Invoking function $\{\mathrm{im} 2 \mathrm{bw}\}$, transforming the grayscale image into the binary image(the dark spot shows the crack, it's grayscale is zero, the white spot is the not cracking partial soil sample,it's gray value is 1 ) ; (5)Invoking function \{imfilter\} to make the image median filter; (6) Invoking function $\{[$ count, $\mathrm{x}]=$ imhist $\}$, count the white and black pixel in the binary image,the ratio of the black pixel to the totle pixel is the fissure ratio. The process is shown in Fig. 2. 


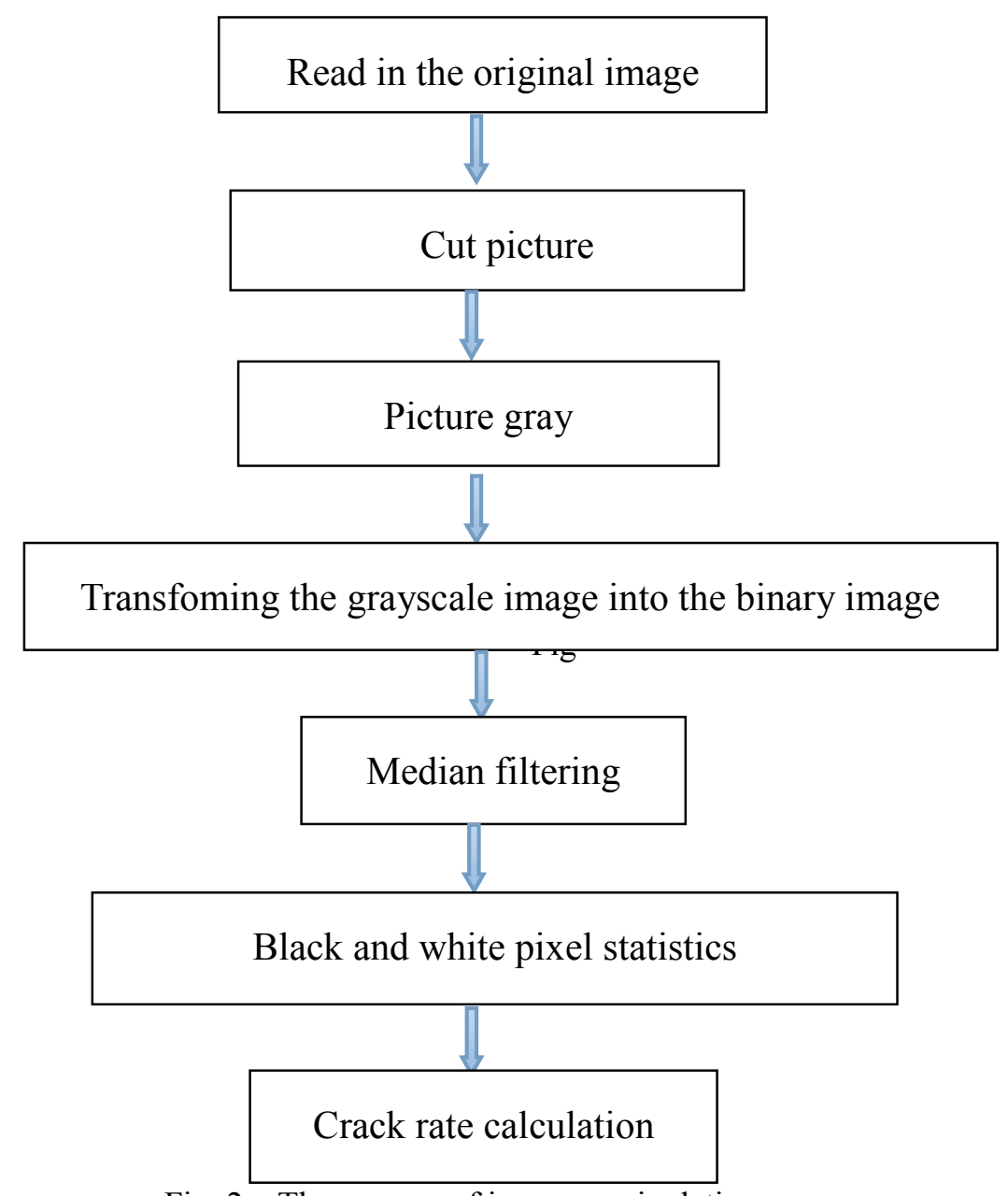

Fig. 2 The process of image manipulation

\section{Testing Results}

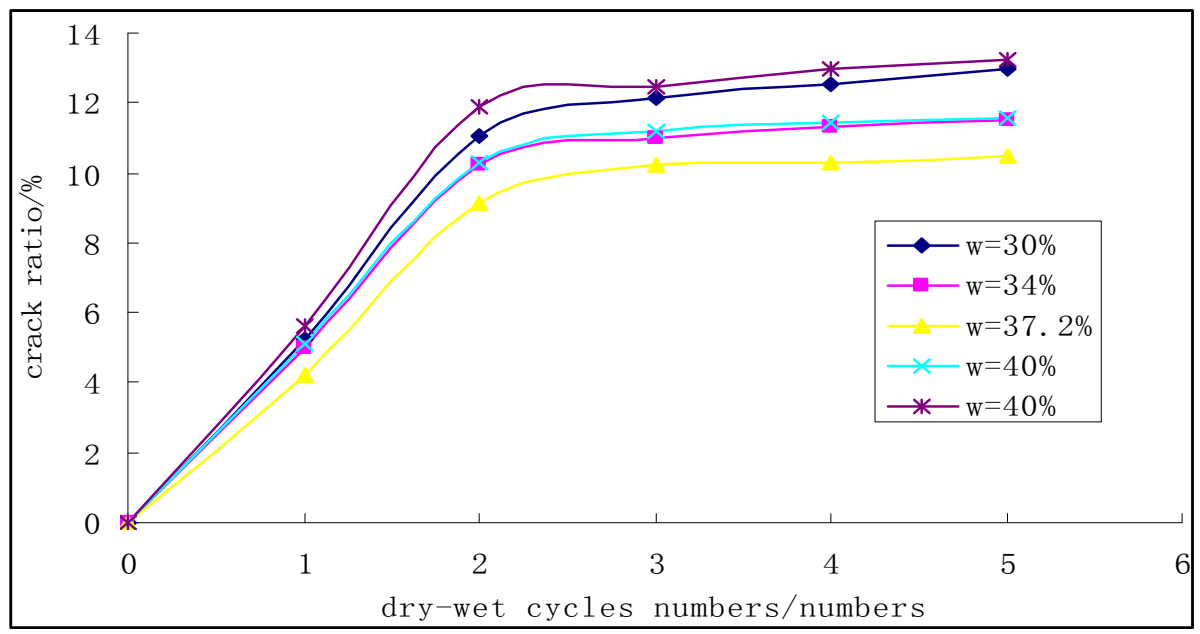

Fig. 3 The relationship between the fissure ratio under the condition of $105^{\circ} \mathrm{C}$ and the number of the wet and dry cycles 


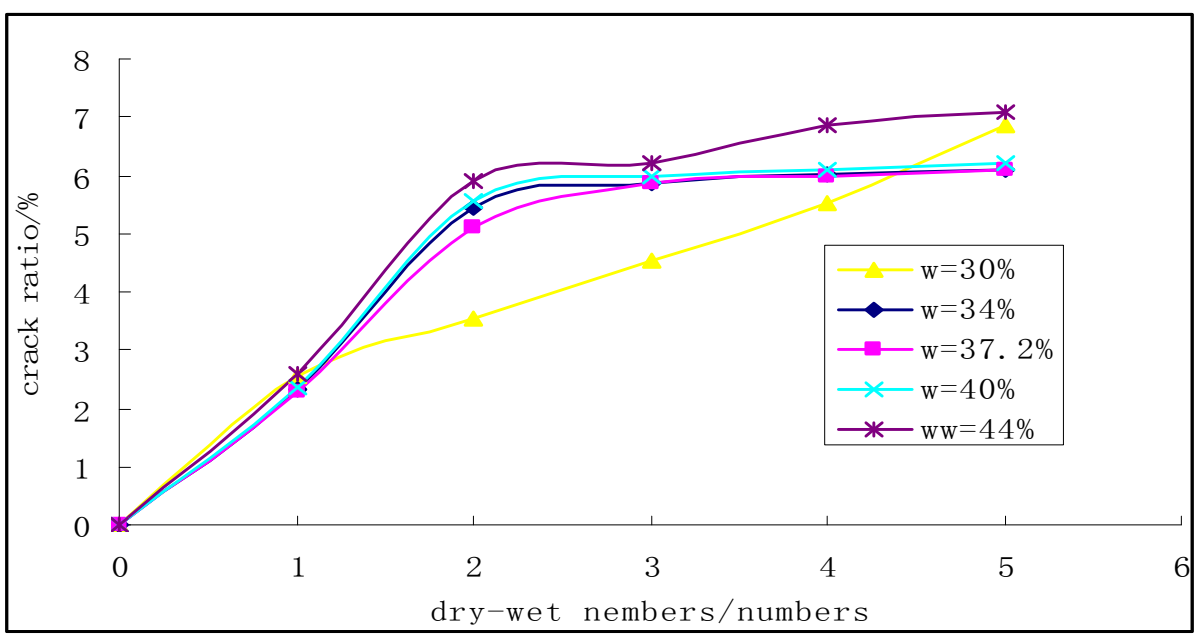

Fig. 4 The relationship between the fissure ratio under the condition of $34^{\circ} \mathrm{C}$ and the number of the wet and dry cycles

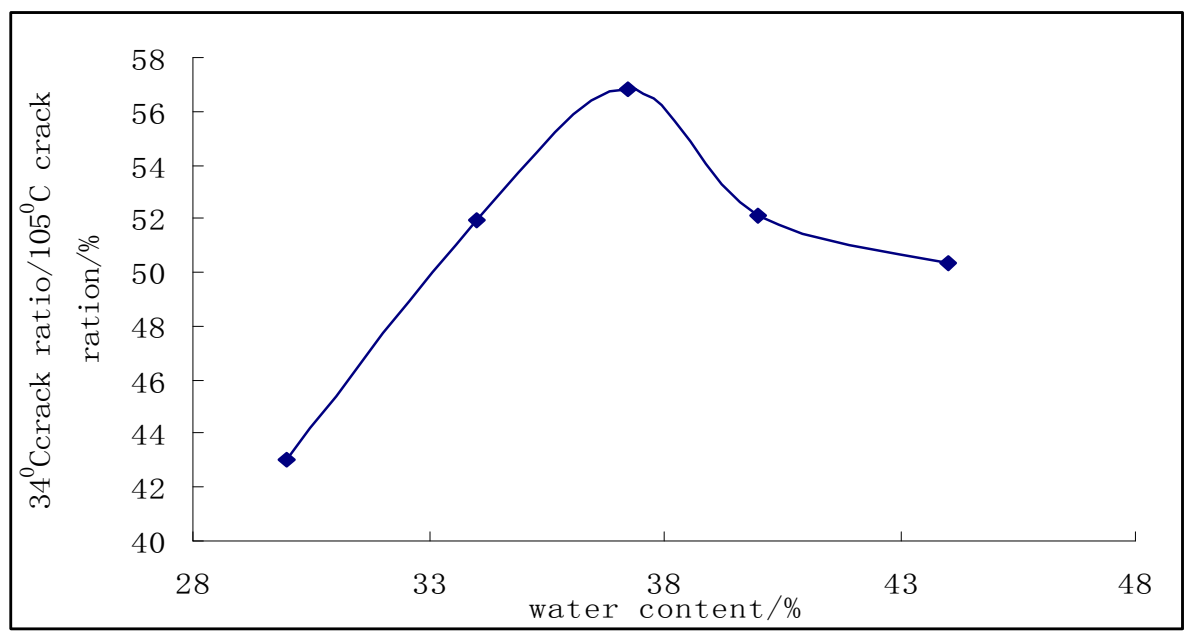

Fig. 5 The relationship between the ratio of fissure ratio under the condition of $34{ }^{\circ} \mathrm{C}$ to under the condition of $105^{\circ} \mathrm{C}$ and the number of the wet and dry cycles

The Fig. 3 and Fig. 4 show that no matter under the condition of $105^{\circ} \mathrm{C}$ or $34^{\circ} \mathrm{C}$, the fissure rate increasing with the increase of the number of the wet and dry cycles.In the first two cycles, the fissure ratio increased significantly, in the last three cycles the fissure ratio increased slowly,explaining the first two cycles have a greater influence on the crack of the red clay.Fig. 5 shows that the ratio of the fissure ratio under the condition of $34^{\circ} \mathrm{C}$ to under the condition of $105^{\circ} \mathrm{C}$ increases fast with the increasing of the moisture content and then reduce,reaching maximum when the moisture content is optimum moisture content.

\section{Conclusions}

The fissure ratio increased with the increase of the numbers of the wet and dry cycles,in the first two cycles it increased significantly, the last three cycles increased slowly, this phenomenon shows that the influence of the first two cycles on the crack of red is larger.

That the ratio of the fissure ratio under the condition $34^{\circ} \mathrm{C}$ to under the condition of $105^{\circ} \mathrm{C}$ increases fast with the increasing of the moisture content and then reduce,reaching the maximum when the moisture content is optimum moisture content. 


\section{Acknowledgements}

This work was financially supported by National Natural Science Foundation of China(Approval number:51368010), Guizhou science and Technology Department—Guizhou University Foundation(Qiankehe Lh zi[2014]7663).

\section{References}

[1]Junping Yuan, Zongze Yin, Chenggang Bao. Quantitative description method and index for fissures in expansive soils.[J]. Journal of Yangtze River Scientific Research Institute, 2003, (6): 27-30(In Chinese)

[2] Xiongwei Li,Xin Feng, Yong Zhang.Depicting and analysis of expansive soil fissure in view of plane.Journal of Hydrogeology \& Engineering Geology,2009, (1): 96-99(In Chinese)

[3] Zaihua Lu,Zhenghan Chen,Yibin Pu.ACT study on the crack evolution of expansive soil during drying and wetting cycles[J].Journal of Rock and Soil Mechanics,2002, (4): 417-422(In Chinese)

[4] Jianping Zhang,Wenping Tao,Zhenchuan $\mathrm{Wu}$,The performance test and construction quality control of red clay road[J].Journal of Foreign highway.,2010(1).(In Chinese)

[5] CedergrenH.R,Drainageofhighwayandairfieldpavements[M ) .NewYork:John Wiley\&Sons, 1974

[6] Junping Yuan, Zongze Yin. Quantitative index of fissure and strength characteristics offissured expansive soil[J]. Journal of Hydraulic Engineering, 2004，(6): 108-113(In Chinese) 